\title{
Genealogia do psíquico. Sobre A transcendência do ego - esboço de uma descrição fenomenológica, de Jean-Paul Sartre
}

Alexandre de Oliveira Torres Carrasco Professor da EFLCH, Universidade Federal de São Paulo 

O texto que segue é um estudo centrado na seção B de A transcendência do Ego, esboço de uma descrição fenomenológica, de Sartre. Ele é parte de um estudo maior, sobre A transcendência do Ego, ainda em curso. Há dois elementos prévios a considerar e que são mencionados indiretamente no texto. O primeiro, a redução ao mínimo a que a versão sartreana da intencionalidade submete o princípio husserliano. O segundo, a conexão estreita que o desenvolvimento específico do cogito, nos quadros da Transcendência do Ego (doravante, TE), tem com a tese do Ego transcendente, elemento chave do ensaio. Pois diferente do cogito cartesiano, operação cuja ausência de resto implica a regra de clareza e distinção, aqui, o resto da operação, seu resto constitutivo, como o chamamos, dar-nos-á as condições teóricas e práticas do psíquico.

Sem tratar diretamente das duas partes do problema, seja a versão sartreana da intencionalidade, seja a genealogia e gramática do psíquico, o interesse específico do problema do cogito, tal como apresentamos, decorre do modo atual como Sartre toma o cogito.

Comecemos com o segundo momento chave da TE. A passagem da consciência de primeiro grau - irrefletida - à consciência de segundo grau - reflexiva. A questão que imediatamente surge é a seguinte: se a consciência irrefletida se dá como síntese de si e de seu objeto no plano (do) imediato sem se confundir em um mesmo plano, ela também se dá como não reflexividade de si no plano do objeto: ela escapa ao plano do objeto, e todas as imagens sartreanas para a consciência - vento, turbilhão, sopro, fuga - figuram, por assim dizer, o momento transcendental da aparição: o si da consciência por não se dar no plano do objeto escapa a qualquer tentativa de posição, de ser posto, vale dizer, de "naturalização". A palavra vai com aspas porque no âmbito da TE, ela assume uma especificidade própria, a certa distância do sentido 
husserliano clássico. Não se dá no plano mundano porque seu momento transcendental não se deixa confundir de maneira naturalista e metafísica com seu objeto. Pois bem, levando isso em conta, o que significaria o segundo grau da consciência, aquele que Sartre começa a descrever por meio da seguinte chamada, o cogito como consciência reflexiva?' A definição clássica do cogito ${ }^{2}$ não nos permite ir muito além da constatação que explica a fór-

1 "Sartre distingue trois degrés de conscience: a) Une conscience de premier degré, irréfléchie, sans Je, non positionnelle de soi, autonome. Elle est un absolu: son existence n'implique pas celle de la conscience réflexive. Lorsque je lis, la conscience de premier degré est la conscience tout entière à l'acte de lire, la conscience absorbée. b) Une conscience de second degré, qui réfléchit et suppose la première, fait paraître le Je, mais reste non thétique de soi. Cogito égologique, la conscience de second degré est celle qui, pertubant ou interrompant la conscience plongée dans la lecture, rapporte le fait de lire à um moi sujet lisant. c) Une conscience de troisème degré, qui se vise en tant conscience réflexive: toute conscience réfléchissante étant en elle-même irréfléchie, "il faut un acte nouveau et du troisième degré pour la poser" (29). Cogito phénoménologie, capable de se réfléchir sans poser de Je, cette conscience s'efforce de saisir sans altération la conscience, irréfléchie ou réflexive, de lecture." (MOUILLIE 2000, p. 45. A descrição de Jean-Marc Mouille de algum modo inova em indicar analiticamente essas três ordens de operação da consciência, tal como descreve na TE, ainda que lá tudo apareça bem menos evidente. No geral, seguimos essa taxionomia. Tomamos a liberdade de pôr entre parênteses o que ele chama de cogito fenomenológico, ainda que concordemos com a descrição feita. A razão é a seguinte: parece-nos que a questão de dar um nome a tal operação ganha um alcance decisivo e que não se trata mais apenas de simplesmente indicar um atributo, a tal operação, "fenomenológico" sem pensar as implicações propriamente fenomenológicas da TE quando da "expulsão" do Ego do âmbito da consciência. Expliquemos. A rigorosa imanência do campo transcendental não deixa de incidir sobre o estatuto da redução (atitude teórica fenomenológica por excelência) e de uma reflexão fenomenológica stricto sensu. Em outros termos, como seria possível "recuar em direção ao fenomenológico" em uma ordem de absoluta imanência? Se o "fenomenológico" não passa imune a esse redimensionamento, seria oportuno explicitá-lo melhor.

2 "Une outre est de penser; et je trouve ici que la pensée est un attribut qui m'appartient: elle seule ne peut être détachée de moi. Je suis, j'existe: cela est certain/mais combien de temps? A savoir autant de temps que je pense; car peut-être se pourrait-il faire, si je cessais de penser, que je cesserais en même temps d'être ou d'exister. Je n'admets maintenant rien que ne soit nécessairement vrai: je ne suis donc, précisément parlant, qu'une chose qui pense, c'est-à-dire un esprit, un entendement ou une raison, qui sont des termes dont la signfication m'était auparavant inconnue" (DESCARTES 1953, p. 277). Vale completar com a seguinte observação de Jean-Marie Beyssade: "Il va du Cogito (vérité portant sur l'ego comme res cogitans) à une seconde vérité, qui ne porte plus sur une res, une chose, et, nomément, qui ne concerne pas l'existence de cette chose infinie et parfaite qu'est Dieu. Le passage est passage à une règle, la "régle générale" (regula generalis, p. 35, ligne 14) qui énconce un critère formel: "tout ce que j'aperçois très clairement et trés distinctement est vrai”. Je ne passe pas d'une res à une res mais, ce qui est fort différent, d'une res à une regula", (BEYSSADE 2001, p. 130). 
mul: eu penso, eu sou. Em tal fórmula está implícita a conjunção que opera a passagem do pensamento ao ser, e é nessa operação que está toda a fama e glória do cogito. Assim, o cogito seria um tipo de atitude (a palavra é excessivamente psicologizante, convenhamos), um tipo de atividade, melhor, um tipo de consciência (já falando em termos anacrônicos) em que o momento constitutivo coincide exatamente e adequadamente com seu objeto (o próprio si da consciência), e isso em um mesmo plano, ao menos em tese. É o que se constata partindo-se do cogito cartesiano. O que nos permitiria dizer que o momento constitutivo - em princípio, o Eu "que pensa" - ao coincidir com seu momento mundano, reencontra-se com a cogitatio (de si) em um mesmo plano, perfaz uma coincidência típica e por isso dá a chave da constituição real do objeto, por meio dessa correspondência/adequação/ coincidência. Daí que a conclusão, o eu que pensa ser aquele que é, é o corolário desse desenvolvimento, já que o "eu" como atividade se encontra com a sua posição mundana e se descobre, além de atividade, como substância.

Neste caso, estamos diante do sentido metafísico da aparição do objeto e da própria noção de "correlação", entendida agora como dedução metafísica. Porque o si - momento constitutivo deixou de ser atividade para ser "coisa" pensante. Temos, enfim, a dedução - no caso cartesiano - do plano real por meio do plano metafísico (análogo ao que chamamos de constitutivo). Uma dedução metafísica e não transcendental, vale lembrar, o que significa que o sentido crítico de "afastamento", de "separar-se" (Ab-sonderung, abs-trahere) não está presente aqui e não poderia ser assimilado ao sentido de "meditação".

Lembremos que essas linhas, que não têm e não pretendem ter nada de original, tão somente ajudam a explicar o problema que abre a seção B da TE (o cogito como consciência reflexiva, i.é, novamente o problema da caracterização da natureza do cogito.

O "eu penso" kantiano é uma condição de possibilidade. O Cogito de Descartes e de Husserl é uma constatação de fato. Fa- 
lou-se da "necessidade de fato" do Cogito e esta expressão parece-me muito justa. Ora, é inegável que o Cogito é pessoal. No "Eu penso" há um Eu que pensa. Atingimos aqui o Eu em sua pureza e é do Cogito que uma "Egologia" deve partir (TE, p. 99).

Mas tão somente indicar o seu sentido metafísico por oposição ao sentido fenomenológico, sem perder de vista, porém, a analogia que se pode estabelecer entre eles. É por meio desse contraste de fundo e de alguma semelhança de superfície que melhor se explica como Sartre acerca-se do cogito.

Com isso em mente podemos suspeitar das complicações que os poderes do cogito causariam ao projeto sartreano na TE. A força e a obscuridade da descrição sartreana da consciência irrefletida decorrem do caráter algo paradoxal da sua operação: unidade sintética anterior à síntese, ela traduz um cruzamento de momentos distintos, que, entretanto, não se confundem: o momento constitutivo e o momento mundano. Como esse cruzamento se dá no imediato (lugar híbrido do concreto), por meio da consciência modo de aparição e aquilo que aparece -, ele adquire um estatuto único: a experiência imediata (toda consciência é consciência de alguma coisa), é a medida da experiência concreta. O que se sucede com a intromissão do cogito? Resumidamente: em seu sentido canônico, a experiência "concreta" (real) passaria a ser medida por meio da experiência reflexiva do Eu (de "si", a maneira do objeto), o que, à primeira vista, usurparia o sentido constitutivo/ real da consciência irrefletida, já que a consciência irrefletida, dada a forma que assume na TE, realizaria a tal coincidência que Descartes crer ser privilégio do cogito formalizar. Expliquemos: aqui, a coincidência ser e pensamento não presta contas a uma esfera reflexiva.

O que diz Sartre:

Mas é necessário lembrar que todos os autores que descreveram o Cogito consideraram-no como uma operação reflexiva, isto é, como uma operação de segundo grau. Este Cogito é operado por uma consciência 
dirigida para a consciência, que toma a consciência como objeto. Entendamos: a certeza do Cogito é absoluta pois, como diz Husserl, há uma identidade indissolúvel da consciência reflexionante e da consciência refletida (na medida em que a consciência reflexionante³ não saberia existir sem a consciência refletida) (TE, p. 99).

Atentemos para os detalhes da descrição, pois ela mantém rigorosamente a operação do cogito em dois planos, a saber, o plano da consciência reflexionante e o plano da consciência reflexiva. Logo, diferentemente da consciência irrefletida, cuja unidade sintética é axiomática, aqui, a unidade do cogito pode ser decupada por meio da navalha de Ockham da consciência irrefletida. A relação da consciência reflexionante vis-à-vis à consciência refletida se esclarece por meio do dispositivo chave da consciência irrefletida - toda consciência é consciência de alguma coisa.

Sigamos, ainda, o texto sartreano:

Ora, minha consciência reflexionante não toma ela própria como objeto quando realizo o Cogito. O que ela afirma concerne à consciência reflexiva. Enquanto minha consciência reflexionante é consciência dela própria, ela é consciência não posicional. Ela apenas se torna posicional à medida que visa à consciência reflexiva (refletida), que não era consciência posicional de si antes de ser reflexiva(refletida). Assim, a consciência que diz "Eu penso" não é precisamente aquela, a reflexionante, que pensa. Ou melhor, não é seu pensamento que ela põe por este ato tético. Nós somos, pois, motivados a nos perguntar se o Eu que pensa é comum às duas consciência superpostas ou se ele não é antes aquele da consciência refletida. Toda consciência reflexionante é, com efeito, nela própria irrefletida e é necessário um novo ato, um de terceiro grau, para a pôr. Não há, aliás, neste caso reenvio ao infinito já que uma consciência não tem de modo algum necessidade de uma consciência reflexionante para

3 Refléchissant, traduzido por "reflexionante" por oposição a "refletido", réflechie (AOTC). 
ser consciência dela mesma. Simplesmente ela não se põe a ela própria como seu objeto (TE, p. 100).

Assim, a consciência reflexionante, tomada como atividade, é irrefletida. O seu sentido "reflexivo" é dado por seu objeto. O seu sentido de "ser" da consciência reflexionate é ser não posicional. Ela não se tematiza ( $a$ si) como atividade - não põe sua atividade no plano do objeto, o que, no limite a inviabilizaria como consciência -, mas, tão somente, toma outra consciência como objeto de sua atividade. A explicação para a afirmação "a consciência que diz 'Eu penso' não é precisamente a que pensa" fica, desse modo, mais clara, porque decorre disso. A consciência refletida tomada como objeto da consciência reflexionante (a consciência "que pensa") aparece (à consciência reflexionante) dissociada de sua unidade sintética originária: seu momento constitutivo (como consciência irrefletida), ao aparecer no mesmo plano que o do objeto, aparece como "eu". Expliquemos: como consciência irrefletida - a consciência que agora é tomada como objeto -, seu momento constitutivo, ao aparecer em unidade com seu momento mundano (objeto), aparece simplesmente como "consciência", de modo que o "de" da fórmula "consciência de" é o meio para indicar que a atividade da consciência não está na consciência como coisa, mas sim na consciência enquanto atividade.

O sentido reflexivo da consciência de segundo grau decorre dessa estruturação: por meio dela é que é possível fazer algo como uma arqueologia sui generis da consciência irrefletida, pois é somente a sua ruína (a submetendo a um regime reflexivo e por meio disso a tomando como refletida) que é possível reconstituí-la, mas sempre como ruína. Assim, é preciso primeiro devastá-la para depois reconstituílla.

Ao ser deslocada para o estado de consciência de uma consciência, o momento constitutivo da então consciência irrefletida degenera-se em "eu", não mais "consciência de", sim "eu" como índice de "consciência". Entendamos esse "eu" do "eu penso" 
- aquele que não pensa: uma vez quebrada a unidade sintética originária da consciência irrefletida, quando caída à condição de consciência refletida (objeto da consciência reflexionante) o nada de seu momento constitutivo - vento, fuga, turbilhão - é alçado à condição de objeto - já que ele não mais pensa, isto é, não se põe como atividade. E ainda que seja nada, atividade que não está no mesmo plano do objeto, a consciência como atividade deve "aparecer" à consciência reflexiva justamente para estruturála: se a consciência reflexiva é uma consciência que se volta sobre outra consciência, essa consciência tomada como objeto não pode "esquecer" sua condição originária de consciência irrefletida, sob pena de aparecer no plano mundano apenas o objeto qualquer da consciência, o que faria da consciência de segunda grau tão somente consciência irrefletida, justamente consciência de um objeto qualquer. Ocorre que, no plano do objeto, esse nada que aparece para dar forma à consciência de segundo grau, só pode aparecer como "falso" objeto justamente para não "falsear" sua condição de nada, quando ainda não fora objeto: um "eu" que não pensa. O sentido reflexivo da consciência de segundo grau, para além do óbvio caráter reflexivo de uma consciência que põe outra consciência como seu objeto, é o de revelar, como reflexividade degenerada, a unidade sintética da consciência irrefletida: os dois momentos da consciência de primeiro grau, no mesmo plano, revelam, por meio de uma "lembrança" transcendental deturpada - o Eu objeto -, a marca transcendental do si em toda consciência - minha consciência, em nível irrefletido, sem eu. Daí o exemplo canônico de Sartre: ao rememorar minha leitura, ao tomá-la como objeto e não como ato, descubro que quando lia, a leitura não exigia um "eu”, um "eu” que lia, não precisava de "mim" para desencadear a operação - ultrapassar as manchas no papel e fazer sentido -, apenas lia como consciência na forma de leitura. Por outro lado, por meio da rememoração dessa leitura, aparece um "eu" como que por detrás das aventuras de Emílio Gauna (Bioy Casares 2005), que lia enquanto a aventura 
se desenrolava diante de(o) mim, um eu que, desviava o olhar, coçava o cabelo, e lia. E ao descrever a operação por meio desses termos, como "lembrança" transcendental, aquela consciência irrefletida paulatinamente ia se degenerando reflexivamente de modo a degradar a própria noção de leitura, que prescinde de eu. A rememoração de que fala Sartre, e que significa, finalmente, que se desloca o sentido constitutivo da atividade da consciência ao tomar a consciência refletida como objeto da consciência reflexionante, é um análogo para explicar o sentido da passagem do irrefletido ao reflexivo. Quando Sartre, no final da passagem supracitada, assevera a não necessidade de uma remissão ao infinito, é também disso que ele está falando: ao ler não preciso de um eu que me garante que leio - e um eu para este eu -, como se o fundamento da atividade (irrefletida) fosse dado pelo que dela revela a reflexão (a consciência de segundo grau). A leitura em ato - consciência como leitura - é índice de si própria, o que significa, por óbvio, que a consciência, dada sua estrutura, é índice de si própria. A descrição que dá Sartre da consciência de segundo grau revela-nos exatamente o contrário: não é o resultado da operação reflexiva que me garante a integridade da operação de primeiro grau. É da rigorosa integridade da operação de primeiro grau que é possível compreender o sentido degenerado da operação de segundo grau.

Por oposição a esta operação, Sartre propõe outra operação como contraprova:

Mas toda consciência irrefletida, sendo consciência não tética dela mesma, deixa uma lembrança não tética que se pode consultar. Para isto basta procurar reconstituir o momento completo em que aparece esta consciência irrefletida (o que é, por definição, sempre possível). Por exemplo, eu estava absorvido um pouco antes em minha leitura. Eu vou procurar me lembrar das circunstâncias de minha leitura, minhas atitudes, as linhas que lia. Eu vou desta maneira ressuscitar não apenas estes detalhes exteriores, mas uma certa espessura da consciência irrefletida, já que os 
objetos não puderam ser percebidos senão por meio dessa consciência e que eles lhe permanecem relativos. Essa consciência, não é necessário a colocar como objeto de minha reflexão, é necessário, ao contrário, que eu dirija minha atenção para os objetos ressuscitados, mas sem a perder de vista, mantendo com ela um tipo de cumplicidade e inventariando seu conteúdo de modo não posicional. O resultado não é duvidoso: enquanto eu lia, havia consciência do livro, do herói do romance, mas o Eu não habitava esta consciência, ela era apenas consciência do objeto e consciência não posicional dela mesma. Esses resultados tomados não teticamente fazem com que eu possa agora fazer deles o objeto de uma tese e declarar: não havia Eu na consciência irrefletida. (TE, p. 101).

Apesar de o sentido dessa outra operação ${ }^{4}$, nossa contraprova, não se dar tão evidentemente no trecho citado, vamos tomá-la da seguinte maneira: o que Sartre propõe é que visemos a uma consciência - uma consciência se dirigindo a outra consciência - sem, entretanto, que desse movimento se origine uma consciência reflexiva, ou ainda, sem que desencadeemos o mecanismo reflexivo, permanecendo essa consciência que se dirige a uma

4 Trata-se do que Jean-Marc Mouille chama de "cogito fenomenológico" (nota 1). "Pour que la réflexion puisse elle-même repérer la modification réflexive, Sartre indique une petite méthodologie: thématiser les circonstances de l'acte remémoré et obtenir par là que paraissent d'eux-mêmes ses caractères originaires dans le sillage de l'acte réflexive. Il s'agit qu'une 'certaine épaisseur de la conscience irreflechie' se dévoile a-thétiquement à travers une réflexion ouverte à la reviviscence de la scène remémorée. L'impression originaire doit venir, pour ainsi dire, miroiter à travers le voile diaphane de la conscience reproductrice. La réflexion devient réflection: comme un miroir, elle laisse venir sur elle des caractères irreflechis." (MOUILLIE 2000, p. 42). Retomando, em parte, as observações da primeira nota desse nosso texto, fica mais clara a amplitude do problema de que falávamos: o fundamento do chamado cogito fenomenológico está, portanto, em um rebaixamento da própria noção de reflexão. Ela não mais se daria como um ato no sentido próprio (o que rebate também no problema da redução - atitude teórica stricto sensu - nesses quadros), mas como reflexo (espécie de continuação esmaecida, duplicação esmaecida?) da atividade irrefletida. Assim, a atividade reflexiva volta a sua própria origem e nada há que possa ser feito fora da ordem do campo transcendental. Diante disso é que perguntamos como poderia haver uma "reflexão" fenomenológica stricto sensu, e se nesse caso Sartre já não estaria em plena exploração de uma seara, de um horizonte, de certo modo, pós-fenomenológico ainda que estritamente "fenomenologizante", na esteira da fenomenologia. 
outra consciência em estado não reflexivo. Parece um truque e tanto e não devemos subestimar os talentos de prestidigitador da consciência irrefletida (e de Sartre). Já víramos que a consciência irrefletida tem disposições únicas: a de ser unidade sintética anterior à possibilidade de síntese parece ser apenas a mais notável. Mas há que explicar que o débito dessa operação não cairia apenas na conta da agramaticalidade da consciência irrefletida, isto é, na sua espontaneidade que reflete aquilo que poderíamos chamar de um certo polimorfismo originário. Há um detalhe analítico que nos permite aproximar-nos melhor do sentido dessa retomada não tética de uma consciência por outra5. Diz Sartre: "essa consciência, não é necessário a colocar como objeto de minha reflexão, é necessário, ao contrário, que eu dirija minha atenção para os objetos ressuscitados, mas sem a perder de vista, mantendo com ela um tipo de cumplicidade e inventariando seu conteúdo de modo não posicional". O que significaria como resultado, como fatura, essa disposição de não colocar a consciência a que se dirige como objeto de minha reflexão? Parece-nos que significaria essencialmente não deslocar para o polo objeto o momento constitutivo da consciência irrefletida. Melhor: essa consciência não teticamente visada não degenera o seu momento constitutivo em um "eu", a forma que o momento constitutivo adquire ao ser deslocado para o plano mundano (do objeto). A não reflexividade dessa contra-operação ou sua reflexividade limitada (por oposição à consciência de segundo grau) decorre do fato que, desse modo, a consciência "objeto" (tomada não teticamente) não apresenta no mesmo plano seu momento constitutivo e seu momento mundano (o Eu e o objeto alinhados na consciência refletida). A consequência imediata disso é que o "eu" não aparece. Como é de se imaginar, a não aparição do Eu está diretamente relacionada com

5 "ces résultats saisis athétiquement (...)" (TE, p. 101). Preferimos traduzir athétiquemente por não teticamente de modo a marcar com clareza a partícula negativa que modifica o termo. 
o modo não tético de apreensão: mantida a distinção de planos da consciência irrefletida nessa consciência não teticamente visada, temos que aquilo que aparece é uma certa "lembrança" constitutiva não degenerada (ainda) da consciência irrefletida: "enquanto eu lia havia consciência do livro, do herói do romance, mas o Eu não habitava essa consciência”.

Todo o esforço em construir essa contraprova tem um fim menos óbvio que o de reiterar o caráter autárquico tantas vezes repetido da consciência irrefletida. Mais importante que essa consequência é a de mostrar, como dado fundamental, o teor da passagem da consciência de primeiro grau para a consciência de segundo grau. $\mathrm{O}$ que ocorre parece ser o seguinte, sumariamente: o momento constitutivo da consciência irrefletida é "falseado" pelo "Eu", que ao se deslocar para o plano do objeto, dá-nos a impressão de que é "ele que pensa”. Isto é, que a consciência irrefletida tem "eu”, em "situação" originária. O que Sartre pretende mostrar nos dois momentos chaves que apresentam a consciência de segundo grau é, muito simplesmente, o seguinte: o "eu” é não apenas um objeto inventado pela queda reflexiva como também um falso objeto - um objeto que dá a impressão de não ser objeto, logo, não corresponde, como objeto, ao objeto que pretende ser -; o "eu" que não pensa ao aparecer como "eu" dá a impressão de que pensa, de que é o polo ativo da operação. Não só a reflexão - a consciência de segundo grau - é derivada como o "eu" que ela institui.

Segue Sartre:

Para isto que uma descrição do cogito nos torna ainda mais sensível. Pode-se dizer que o ato reflexivo apreende com o mesmo grau e da mesma maneira o Eu e a consciência pensante? Husserl insiste sobre o fato de que a certeza do ato reflexivo decorre de que lá se apreende a consciência sem facetas, sem perfis, completamente inteira (sem "Abschattungen"). Evidentemente. Ao contrário, o objeto espaço-temporal entrega-se sempre por meio de uma infinidade de aspectos e não é, no fundo, senão 
a unidade ideal desta infinidade de aspectos. Quanto às significações, às verdades eternas, elas afirmam sua transcendência pelo fato que elas se dão desde que são independentes do tempo, enquanto a consciência que as apreende é, ao contrário, rigorosamente individualizada na duração. Ora, perguntamos: quando uma consciência reflexiva apreende o Eu penso, é dado a ela apreender uma consciência plena e concreta recolhida em um momento real da duração concreta? A resposta é clara: o Eu não se dá como um momento concreto, uma estrutura perecível de minha consciência atual. Ele afirma, ao contrário, sua permanência para além dessa consciência e de todas as consciências e - ainda que, por certo, ele praticamente não se assemelha a uma verdade matemática seu tipo de existência reaproxima-se bem mais do tipo de existências das verdades eternas que do tipo de existência da consciência. É mesmo evidente que é por ter acreditado que o Eu e penso são no mesmo plano que Descartes passou do cogito à idéia de substância pensante (TE, p. 102).

Tomemos o fim da passagem. Podemos nos aproximar do Sartre crítico de Descartes entendendo o ultracartesianismo sartreano como mais uma volta no parafuso antinaturalista ${ }^{6}$. Expliquemos: o equívoco cartesiano - o Eu e o penso no mesmo plano - significaria que o "eu que pensa" (não se trata de "eu", como vimos, mas da consciência irrefletida, sempre consciência não posicional de si e consciência de um objeto qualquer) seria um objeto transcendente deslocado do fluxo espaço temporal, da duração, e simultaneamente, objeto da duração, isto é, atividade. O fato de o pensamento pôr a existência, em sentido metafísico, decorreria disso: o Eu como "coisa" que "age". Nesse caso, a atividade constitutiva da consciência, rebaixada à condição de coisa (“coisa pensante", vá lá, na forma do "Eu”) expulsa para longe do campo dos fenômenos, daquilo que aparece, o modo pelo qual qualquer coisa aparece. O mecanismo - antimecanicista, diga- 
mos assim, abusando um pouco do maneirismo - originário da consciência (o segredo de polichinelo "toda consciência é consciência de alguma coisa”), rebaixada a consciência à condição de objeto na forma de "Eu", perde seus direitos constitutivos e passa a ter apenas direitos delegados de Deus, garantidor metafísico de última instância.

O propósito sartreano, entretanto, parece mais sutil que desarmar as pretensões do cogito cartesiano. Certamente que a coincidência metafísica de que o cogito cartesiano pretende ser índice, na sua prima versão, é abandonada, já que não há alinhamento em um mesmo plano do "eu" e do "penso". O "eu" que não pensa ("eu” que sempre aparece no polo objeto) aparece, agora na consciência de segundo grau, justamente porque seu pressuposto é uma consciência irrefletida que, naturalmente, dispensa o "Eu". Ocorre, e este é o fato para o qual se encaminha a análise, que um "eu” aparece. Que ele não esteja presente na estrutura originária da consciência como objeto, que não seja possível flagrá-lo em uma consciência individualizada na duração, porque ela é atividade que permanece atividade, não impede que ele apareça, sob a condição de que seja desencadeada essa operação reflexiva. E qual a natureza desse "eu"? Ele aparece como objeto que permanece para além da duração, que não se alimenta da duração concreta, porque sua "presença" não pode ser apontada. Tal como uma "verdade eterna" esse "eu" aparece como que pairando acima da consciência. Sem abusar do termo, poderíamos dizer que para a ilusão transcendental que ele produz - dar a "aparência" de estar no mesmo plano do "eu" que pensa, da atividade da consciência reflexionante, dar a "aparência" de que ele é o "eu" que pensa, o eu como sede daquela atividade - já foi previamente preparada a crítica com a rigorosa descrição da consciência irrefletida. A inegável aparição do "Eu”, porém, não deixa de exigir ainda mais: que sua natureza seja desvendada.

Esta é a palavra de ordem para o que segue: 
Sejamos mais radicais e afirmemos sem temor que toda transcendência

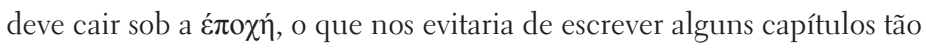
embaraçantes quanto o parágrafo 6ı de Ideen. Dado que o Eu se afirma como transcendente no "Eu penso", ele não é da mesma natureza que a consciência transcendental" (TE, p. 103).

Como o "eu” aparece à consciência? Como habitante que não participa da estrutura mesma da consciência. "Eu” como centro de opacidade: não apenas por ser objeto transcendente mas também por ser objeto transcendente fora da economia dos Abschattungen, dos perfis, fora do campo transcendental. O "Eu”, com suas características de objeto transcendente, instaura uma ordem de não coincidência entre o ser o parecer. Daí também sua opacidade.

Eis as conclusões a que chega Sartre:

Concluindo esta análise, parece-me ser possível fazer as seguintes constatações:

1) O eu é um existente. Ele tem um tipo de existência concreta, diferente sem dúvida daquela das verdades matemática, das significações ou dos seres espaço-temporais, mas igualmente real. Ele se dá ele próprio como transcendente.

2) Ele se entrega a uma intuição de um gênero especial que o toma por detrás da consciência reflexiva, de um modo sempre inadequado.

3) Ele nunca aparece senão por ocasião de um ato reflexivo. Neste caso, a estrutura complexa da consciência é a seguinte: há um ato irrefletido de reflexão sem Eu que se dirige sobre uma consciência refletida. Esta se torna o objeto da consciência reflexionante sem cessar, entretanto, de afirmar seu próprio objeto (uma cadeira, uma verdade matemática etc.). Ao mesmo tempo um novo objeto aparece que é a ocasião de uma afirmação da consciência reflexiva e que não está, por conseguinte, nem sobre o mesmo plano da consciência irrefletida (porque esta é um absoluto que não tem necessidade da consciência reflexiva para existir) nem sobre o mesmo plano do objeto da consciência irrefletida (cadeira etc.). Este objeto transcendente do ato reflexivo é o Eu. 
4) O Eu transcendente deve cair sob o golpe da redução fenomenológica. O Cogito afirma demais. O conteúdo certo do pseudo "Cogito" não é "eu tenho consciência desta cadeira", mas "há consciência desta cadeira". Este conteúdo é suficiente para constituir um campo infinito e absoluto de pesquisas para a fenomenologia (TE, p. 104).

Tudo isso colocado, e com intenção de dar um primeiro fecho provisório para a exposição, podemos fazer um resumo a trote ligeiro, allegro ma non tropo, acompanhando o ritmo algo ansioso do próprio artigo.

A partir da análise dessas duas primeira seções, a descrição da estrutura original da consciência avança na exata medida em que nos damos conta que se "a consciência toma consciência de si enquanto ela é consciência de um objeto transcendente", na ordem do campo transcendental, o modo de aparição é estruturalmente idêntico ao modo de constituição. E segue Sartre “tudo, pois, é claro e lúcido à consciência: o objeto está diante dela com sua opacidade característica, mas ela é pura e simplesmente consciência de ser consciência deste objeto". Ora esta "dupla” consciência sobreposta - consciência de ser consciência de um objeto qualquer - não é, como as aspas sugerem, "dupla” no sentido da atitude natural, de novo, consciência $e$ consciência de ser consciência, mas duplo efeito - consciência e - ela mesma - consciência de um objeto qualquer - gerado pela estrutura originária da consciência.

E que pode ser traduzido pela constatação que esta consciência é consciência de um objeto qualquer e consciência não posicional de si. Síntese anterior à possibilidade de síntese, essa unidade forma a pedra de toque constitutiva por excelência. Retomemos: consciência não posicional significa que a consciência não é ela própria seu objeto. Sartre não se furta em dispensar qualquer aparato que acompanhe a atividade constante desta consciência, simplesmente porque ele é dispensável. (Vimos que ele não só é dispensável como funesto). 
Todo o esforço em cristalizar, em precipitar esta definição da estrutura originária da consciência, Sartre faz com a intenção de afastar a necessidade da presença formal de um "Eu" que acompanhe a consciência, alterando radicalmente o sentido de representação, constituição e instituição ${ }^{7}$.

$\mathrm{Na}$ segundo seção (Cogito como consciência reflexiva) o problema passa a ser a presença "reflexiva" de um "Eu" inscrito na "estrutura" da consciência. Daí o cogito, constatação de fato - como indica a Segunda Meditação -, indicar o problema de

7 Detenhamo-nos um pouco em torno dos problemas da presença material do "Eu".

A seção C da TE, "Teoria da presença material do Eu" aparece imediatamente após a seção do cogito. À primeira leitura, tem-se a nítida impressão de que o assunto está "fora de lugar", já que depois de densos parágrafos sobre a estrutura reflexiva da consciência, voltaríamos a um problema meramente psicológico, para não dizer de psicologia vulgar (a psicologia do amor próprio). Uma leitura um pouco mais detida, pode indicar outra coisa. Vejamos:

"Ora, o interesse desta tese nos parece ser o de pôr em relevo um erro muito frequente dos psicólogos: ele consiste em confundir a estrutura essencial dos atos reflexivos com aquela dos atos irrefletidos. Ignora-se que sempre há duas formas de existência possíveis para uma consciência, e, cada vez que as consciências observadas se dão como irrefletidas, sobrepõe-se-lhes uma estrutura reflexiva que se pretende imprudentemente que ela permaneça inconsciente" (TE, p. 105.

O problema propriamente psicológico encobre, de fato, um problema maior: o problema da duplicação do Ego transcendental que, uma vez havendo, deve coincidir e se diferenciar "adequadamente" para seu duplo empírico. A inversão que a reflexão vulgar implica é justamente a de tomar a consciência de segundo grau como fundamento da consciência irrefletida. Nessa inversão está pressuposto o fato de que lá, na estrutura da consciência de segundo grau, o "eu" que aparece seria o núcleo a partir do qual se irradiaria o fundamento do desejo, agora tomado como objeto transcendente.

Parece, assim, mais uma vez, que o problema se volta para a o "núcleo metafísico" da fenomenologia, a saber, a indistinção entre o transcendental e o empírico na forma de "presença”. Podemos voltar a Derrida:

"Toutes ces difficultés se concentrent dans le concept énigmatique de "parallélité" et même, "si l'on peut dire, le recouvrement" de la psichologie phénoménologique et de la phénoménologie transcendental, "toutes deux comprises comme disciplines éidétiques". "L'une habite l'autre, si l'on peut dire, implicitement." Ce rien qui distingue des parallèles, ce rien sans lequel justement aucune explicitation, c'est-à-dire aucun langage ne pourrait se déployer librement dans la vérité sans être déformé par quelque milieu réel, ce rien sans lequel aucune question transcendantale, c'est-à-dire philosophique, ne pourrait prendre souffle, ce rien surgit, si l'on peut dire, lorque la totalité du monde est neutralisé dans son existence et réduite à son phénomène. Cette opération est celle de la rédution transcendantale, elle ne peut être em aucun cas celle de la réduction psycho-phénoménologique. L'éidétique pure du vécu psychique ne concerne sans doute aucune existence déterminé, aucune factualité empirique; elle ne fait appel à aucune signification transcendante à la conscience.” (DERRIDA 2009, p. 12). 
presença material de um "Mim" qualquer à consciência. Sartre parece tomar as conclusões a que se chega com o cogito como ponto de partida: é dado como irrefutável que o cogito é pessoal, que há um eu que pensa ou parece pensar. Assim: "cada vez que apreendemos nosso pensamento, seja por meio de uma intuição imediata, seja por meio de uma intuição apoiada na memória, apreendemos um Eu que é o Eu do pensamento apreendido e que se dá, além do mais, como transcendendo este pensamento e todos os outros pensamentos possíveis".

E Sartre segue até o fim deste primeiro parágrafo desta segunda seção garantindo que "ao me lembrar da paisagem percebida em uma viagem qualquer, eu posso me lembrar que eu via esta paisagem".

Cabe agora explicar como este eu aparece e qual o seu estatuto - já delineado por meio do modo pelo qual aparece: na medida que este Eu apreendido é apreendido como um objeto transcendente, a investigação caminha para a descrição dessa sua natureza transcendente.

A partir desta indicação em filigrana e tomando a descrição sumária que dá Sartre do cogito, podemos tentar resumir o percurso sartreano que é aquele que culmina neste $E u$ transcendente por meio do cogito. Ora o que é o cogito? Responde Sartre: "o cogito é operado por uma consciência dirigida sobre a consciência, que toma a consciência como objeto".

A partir deste ponto a operação do cogito dar-se-á de tal modo que não será necessária à presença do Eu: a certeza absoluta do cogito, a certeza de que eu tenho consciência, que tive consciência, se dá por meio de uma "unidade indissolúvel da consciência reflexionante e da consciência refletida (a ponto de a consciência reflexionante não poder existir sem a consciência refletida)". Como bem observa Sartre, com esta constatação retornamos a cláusula pétrea da fenomenologia: toda consciência é consciência de alguma coisa.

Eis uma das consequências do retorno a esta conhecida cláusula: 
Ora, minha consciência reflexionante não se toma ela própria por objeto quando eu realizo o Cogito. O que ela afirma concerne à consciência refletida. Enquanto minha consciência reflexionante é consciência dela própria, ela é consciência não posicional (TE, p. 100).

Ora, até esta altura parece não haver maiores complicações: o mecanismo fundamental de atividade da consciência se desdobra em nível reflexivo.

Segue Sartre: “[Esta consciência] não se torna posicional senão em visando a consciência refletida que, ela mesma, não seria posicional de si antes de ser refletida. Assim, a consciência que diz 'Eu penso' não é precisamente aquela que pensa”. Observemos como se processa a análise: a consciência reflexionante toma uma consciência irrefletida qualquer e esta apreensão é tal que muda a situação "estrutural" da consciência irrefletida: se antes consciência e objeto estavam inscritos em uma unidade originária que se efetiva no imediato (lugar do concreto) e conforme essa "estrutura" dinâmica da consciência, o objeto qualquer coincide necessariamente com a própria atividade da consciência, agora, a "consciência” (não mais consciência stricto sensu, mas lembrança da consciência na forma de objeto) se dá como um objeto transcendente apreendido por uma consciência de segundo grau. E por que consciência de segundo grau? Porque ela não apreende (ou a ela não se dá) apenas o objeto qualquer, mas a "consciência" deste objeto (a maneira de ficção transcendental), o que implica que ela apreende esta consciência, em linguagem técnica, põe e toma não apenas o objeto mas também a consciência. Isto torna possível que a consciência intua, para além do objeto qualquer, a consciência correlata deste objeto, já dele dissociada na consciência reflexiva (como consciência refletida, objeto da consciência reflexionante), o que torna possível a aparição de um certo "Eu”.

Daí que as perguntas que abrem o parágrafo seguinte, todas, pretendem responder como este "Eu” aparece, como se dá, por 
que meios ele aparece. Ora, o problema é mostrar em que medida este "eu" que aparece se inscreve ou não na estrutura da consciência (seja reflexiva ou não). O que significa a aparição do Eu? Vale insistir que este "Eu" reiteradamente mencionado não é ainda o "Eu" objeto transcendente da ordem do psíquico, também "ficção transcendental" por excelência, com a ressalva de ter a especificidade do psíquico. O que não significa, por outro lado, que esse "eu", objeto da consciência reflexionante, (e parte necessária da estrutura da consciência de segundo grau) não seja um ancestral do "Eu" que aparece e funda a região do psíquico, o australopiteco do homo sapiens.

Sartre reconstrói o caminho que vai da consciência irrefletida às cercanias deste "eu" por meio da operação reflexionante, de segundo grau. A grande novidade, não muito alardeada, dessa operação é o aparecimento de um "eu" algo bastardo, parte da consciência refletida, objeto da consciência reflexionante. Este "eu", resíduo de uma operação que continua guardando para si a transparência e translucidez da consciência irrefletida - que a fundamenta - parece criar as condições necessárias para uma Egologia. Assim, é sua aparição, cercada de tantos "senãos" que passa a ser o fio da TE: resíduo de uma operação de segundo grau, a investigação passa a se centrar na "capacidade" desse "eu" em afirmar mais do que ele pode afirmar - seu caráter mistificador que decorre de sua natureza de ficção transcendental.

Notemos, aliás, que ele não aparece para a reflexão como consciência refletida: ele se dá por meio da consciência refletida. Por certo que ele é apreendido pela intuição e é objeto de uma evidência. Mas sabe-se o serviço que Husserl prestou à filosofia distinguindo diversas espécies de evidência. Desta maneira, é muito certo que o Eu do Eu penso não é objeto de uma evidência nem apodítica nem adequada. Ela não é apodítica já que quando se diz Eu afirmamos muito mais do que sabemos. Ela não é adequada pois o eu se apresenta como uma realidade opaca em relação a qual seria necessário desdobrar o conteúdo. Seguramente 
ele se manifesta como a fonte da consciência, mas isto nos deveria levar a refletir: com efeito, ele aparece velado, mal distinto por meio da consciência, como uma pedra no fundo da água - deste fato segue-se que ele é enganador, pois nós sabemos que nada, exceto a consciência, pode ser a fonte da consciência (TE, p. 103).

\section{Bibliografia \& Indicação de citação das obras de Sartre e Merleau-Ponty}

\section{Obras de Sartre}

TE2 - "La transcendance de l'ego" in Recherches philosophiques $1937, n^{\circ} 6$.

TE1 - La trancendance de l'ego, esquisse d'une description phénoménologique 1988, introdução, notas e apêndices por Sylvie Le Bon, Paris, Vrin.

TE - La transcendance de l'ego et autres textes phénoménologiques 2003 , textos introduzidos e anotados por V. Coorebyter, Paris, Vrin. IfphI - "Une idée fondamentale de la phénoménlogie de Husserl: l'intencionalité" in N.R.F., janeiro de 1939.

IfphIl - "Une idée fondamentale de la phénoménlogie de Husserl: l'intencionalité" in La transcendance de l'ego et autres textes phénoménologiques 2003 , textos introduzidos e anotados por V. Coorebyter, Paris, Vrin.

Imaginação - L'imagination 1936, Paris, Presses Universitaires de France.

ETE - Esquisse d'une théorie des emotions 1938, Paris, Livre de poche.

Imaginário - L’imaginaire 1940, Paris, Gallimard.

EN - L'être et le neant 1943, Paris, Gallimard.

CDG - Carnets de la drôle de guerre 1995, Paris, Gallimard. 


\section{Bibliografia geral}

BEYSSADE, Jean-Marie, Études sur Descartes. Paris: Éditions du Seuil, 2001.

BIOY CASARES, Adolfo, El sueño de los héroes. Ed. La Nacion, 2005

DERRIDA, J., La voix et le phénomène. Paris: PUF, 2009.

DESCARTES, R., Oeuvres 6 Lettres. Paris: Pleiade/Gallimard, 1953.

MOUILLIE, Jean-Marc, Sartre, conscience, ego et psyche. Paris:

PUF, 2000 . 
